\title{
Research on the Volatile Organic Compounds in the Air after Indoor Decoration Pollution Status and Pollution Control Countermeasures
}

\author{
Yunfei Wang ${ }^{1}$ \\ 1 Jiyuan Vocational and Technical College, \\ Jiyuan ,Henan,454650 China
}

\begin{abstract}
In this paper, we conduct research on the volatile organic compounds in the air after indoor decoration pollution status and pollution control countermeasures. The concentration and particle size of particulate matter in indoor air distribution is an important index of indoor air quality evaluation. Although people have the choice to decorate material of environmental protection consciousness, however, the current building materials on the market of decorate material to the good and bad are intermingled. Our research provides countermeasures to the troublesome issues.
\end{abstract}

Keywords: Volatile Organic Compounds; Indoor Decoration; Pollution Status; Countermeasures.

\section{Introduction}

With the improvement of living standard and life style changes, people more and more time living and working in indoor, indoor air quality has become an important part of working and living environment. Poor air quality makes the person feels uncomfortable, distracted and largely reduces the work efficiency. In recent years, research has shown that not only exists in indoor air can be sucked suspended particles, asbestos, heavy metals, radioactive substances, inorganic pollutants such as the carbon monoxide, ozone, nitrogen dioxide, but also exist polycyclic aromatic hydrocarbons, volatile organic compounds, aldehydes and other organic pollutants. A considerable number of these organic pollutants have causes the cancer or birth defects, and we can also and the reaction such as the material in air into stronger compounds causes cancer or birth defects. Indoor air quality is not only affected by the penetration and diffusion of outdoor air pollutants, and the influence of indoor air pollution. Such as cooking, heating, smoking, building and decoration materials of volatile and release, the release of household electrical appliances, office facilities, emissions, etc. At the same time, with the development of the construction technology and the attention to energy storage, indoor ventilation rate gradually decreases than before, indoor air pollution emissions of pollutants in the indoor air pollution is more and more big proportion. When indoor pollution sources, such as heating, cooking, smoking, if it does not have good ventilation conditions, indoor air of organic pollutant concentration of carcinogenic, teratogenic and related will be much higher than outdoor [1].

The sources of the air pollution for the indoor condition could be summarized as the follows. (1) Building decoration materials. Warm up as interior decoration and building airtight degree increase, a large number of volatile harmful toxic substances of all kinds of building decoration materials, man-made board furniture enter indoor, indoor kinds and concentrations of harmful substances significantly increased than in the past, the serious influence indoor and the health of the residents. (2) Humans add charm. Indoor air pollution caused by household decorates is related to people's health, and the focus of concern is the social problem. According to the relevant departments of the test results, in the new decorating a bedroom, indoor is the main pollutants of formaldehyde and formaldehyde as the most common in indoor air pollution and 
harm to human body health is the most serious pollution which has become a top priority to solve indoor environment pollution control.

The concentration and particle size of particulate matter in indoor air distribution is an important index of indoor air quality evaluation. In indoor air of different size particles on the content is not the same, in the human respiratory organs deposition area and relative deposit amount is not the same, the harm to human health caused by is not the same. Therefore, particle size distribution in the air, research within the scope of different size particles of the content is very important. Because the child is a very special group which is resistance to outside harmful factor is very weak. Longest day of the bedroom, its air quality is good or bad influence on children's physical health. Long-term exposure to formaldehyde can cause the respiratory disease which also can cause children's physique to reduce, chromosomal abnormalities, and even cause serious consequences such as the nasopharyngeal carcinoma. In the figure one, we illustrate the influence of the indoor air pollution.

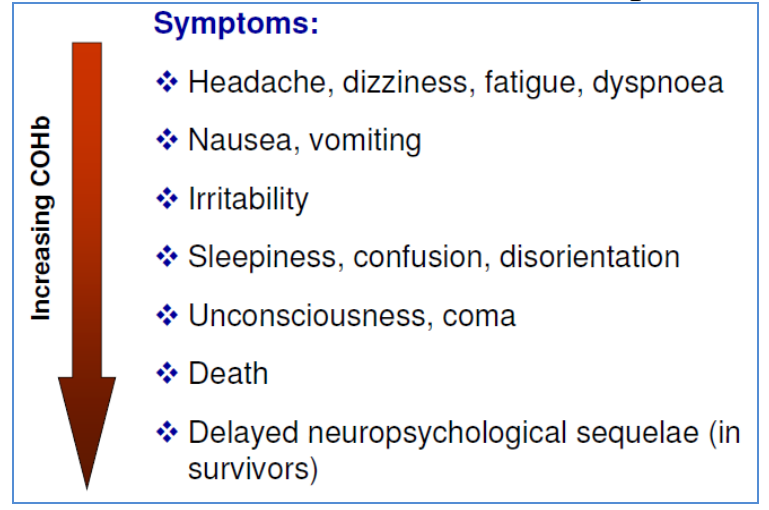

Figure 1. The Influence of the Indoor Pollution after Indoor Decoration
In this paper, we conduct research on the volatile organic compounds in the air after indoor decoration pollution status and pollution control countermeasures. Indoor air quality problems more and more get people's attention. However, with the improvement of people's living standard, more and more people focus on office, beautiful and comfortable bedroom, indoor decoration rising heat, but ignored the decoration materials used will release toxic or harmful gases. In the following parts, we will discuss and research the issues in detail from different perspectives.

\section{The Proposed Methodology}

The Volatile Organic Compounds in the Air. Formaldehyde which is higher because the study room is equipped with independent study, there is a complete set of the bookcase, the bookcase or purchase or whole decorate, visible plank is still the main cause of indoor formaldehyde pollution, detecting data use well-known brand furniture room formaldehyde content is low; Restaurant because of its simple decoration, formaldehyde content is low. In the detection of the sitting room, we found that, when in the sitting room furniture is more, especially with a sofa, the indoor formaldehyde content is higher shows that sofa materials and its processing is the secondary pollution caused by indoor air is an important reason. The figure two illustrates the major pollution for indoor condition. 


\begin{tabular}{|c|c|c|c|c|c|}
\hline Compound & Formula & CAS-no. & $\mathrm{M}(\mathrm{g} / \mathrm{mol})$ & b.p. $\left({ }^{\circ} \mathrm{C}\right)$ & $\log \left(P_{s}\right)(P a)$ \\
\hline 2-Methylfuran & $\left(\mathrm{C}_{4} \mathrm{H}_{3} \mathrm{O}\right) \mathrm{CH}_{3}$ & $534-22-5$ & 82.1 & 64.7 & 4.32 \\
\hline 2-Methyl-3-buten-1-ol ${ }^{\mathrm{b}}$ & $\left(\mathrm{CH}_{3}\right)_{2} \mathrm{C}(\mathrm{OH}) \mathrm{CHCH}_{2}$ & $115-18-4$ & 86.1 & 97.0 & 3.49 \\
\hline Furfural $^{\mathrm{b}}$ & $\left(\mathrm{C}_{4} \mathrm{H}_{3} \mathrm{O}\right) \mathrm{CHO}$ & $98-01-1$ & 96.1 & 161.8 & 2.47 \\
\hline$n-$ Hexane $^{b}$ & $\mathrm{C}_{6} \mathrm{H}_{14}$ & $110-54-3$ & 86.2 & 69.0 & 4.30 \\
\hline 2-Methylpentane & $\mathrm{CH}_{3} \mathrm{CH}\left(\mathrm{CH}_{3}\right) \mathrm{C}_{3} \mathrm{H}_{7}$ & $107-83-5$ & 86.2 & 60.2 & 4.45 \\
\hline 3-Methylpentane & $\mathrm{C}_{2} \mathrm{H}_{5} \mathrm{CH}\left(\mathrm{CH}_{3}\right) \mathrm{C}_{2} \mathrm{H}_{5}$ & $96-14-0$ & 86.2 & 63.3 & 4.40 \\
\hline Diisopropylether ${ }^{b}$ & $\left(\mathrm{CH}_{3}\right)_{2} \mathrm{CHOCH}\left(\mathrm{CH}_{3}\right)_{2}$ & $108-20-3$ & 102.2 & 68.4 & 4.30 \\
\hline Carbon disulfide & $\mathrm{CS}_{2}$ & 75-15-0 & 76.1 & 46.0 & 4.68 \\
\hline Methylsulfide & $\mathrm{HSCH}_{3}$ & $74-93-1$ & 48.1 & 5.9 & 5.30 \\
\hline Dimethylsulfide & $\mathrm{S}\left(\mathrm{CH}_{3}\right)_{2}$ & $75-18-3$ & 62.1 & 37.3 & 4.83 \\
\hline Trimethylsilanol & $\mathrm{Si}\left(\mathrm{CH}_{3}\right)_{3} \mathrm{OH}$ & $1066-40-6$ & 90.2 & 97.8 & 3.27 \\
\hline Acrylonitrile & $\mathrm{CH}_{2} \mathrm{CHCN}$ & $107-13-1$ & 53.1 & 77.3 & 4.16 \\
\hline Acetonitrile & $\mathrm{CH}_{3} \mathrm{CN}$ & $75-05-8$ & 41.1 & 81.7 & 4.07 \\
\hline Dimethylamine & $\mathrm{HN}\left(\mathrm{CH}_{3}\right)_{2}$ & $124-40-3$ & 45.1 & 7.4 & 5.55 \\
\hline Trimethylamine & $\mathrm{N}\left(\mathrm{CH}_{3}\right)$ & $75-50-3$ & 59.1 & 2.9 & 5.33 \\
\hline Diethylamine & $\mathrm{HN}\left(\mathrm{C}_{2} \mathrm{H}_{5}\right)_{2}$ & $109-89-7$ & 73.1 & 56.1 & 4.50 \\
\hline Triethylamine $^{\mathrm{b}}$ & $\mathrm{N}\left(\mathrm{C}_{2} \mathrm{H}_{5}\right)_{3}$ & $121-44-8$ & 101.2 & 89.3 & 3.88 \\
\hline Dimethylformamideb & $\mathrm{N}\left(\mathrm{CH}_{3}\right)_{2} \mathrm{CHO}$ & $68-12-2$ & 73.1 & 153.0 & 2.71 \\
\hline
\end{tabular}

Figure 2. The Major Pollution in the Indoor Condition and Environment

Bedroom air quality refers to a certain area and time, contaminated air is contained in the test to achieve a stable readings. Main standard particles, formaldehyde content, oxygen content, moisture content are used to indicate an important index of environmental health and living environment. Acceptable bedroom air quality is in the bedroom of the general public place, most people don't have the bedroom air express strong dissatisfaction and pollutant concentration has not reached to the extent of the poses a major threat to the human health condition [2].

The Pollution Control Countermeasures. Various kinds of methods for determination of formaldehyde concentration in the air, including phenol reagent spectrophotometry as arbitration law to color fast, high sensitivity and test results are accurate which is widely used in the laboratory. Combining with the actual, the formaldehyde content in the air in the bedroom of selected with this method for testing, in decorating a different time, room type at different time under different conditions and detection of formaldehyde pollution which can be more comprehensive understanding of family status of indoor formaldehyde pollution in the air after decorating, force to control indoor air pollution, provide a scientific basis for improving indoor environment quality and methods, in order to meet the needs of people for health residential. In decorating after six months, formaldehyde concentration in indoor air can drop to the content of standard limit prescribed by the state. Formaldehyde concentration, however, did not decrease with time, but there is a rise in process first, then decrease. Appear this kind of circumstance is mainly based on the following reasons: formaldehyde is volatile organic compounds, volatile slowly, for a long time. Many consumers to ignore the influence of decorative materials and furniture, interior formaldehyde mainly comes from plywood, adhesive, interior wall coating and wallpaper decoration materials, and on the market of solid wood furniture basically is to use a variety of man-made board, these materials often cannot meet the requirements of environmental protection, thus new furniture will continue to indoor formaldehyde release which will increase the concentration of formaldehyde.

Through detection of newly renovated bedroom formaldehyde in the air and pollution situation analysis shows that the present new decoration of formaldehyde pollution in the air inside the bedroom is in serious condition. Town to take the following measures for prevention and treatment: (1) Air purification. This method is 
mainly by ion exchange and catalysis technology decomposes harmful gases. Or use special enzyme biological oxidation harmful gas. Or put in indoor plants with adsorption. Optimization design. Ensure the ventilated smooth, when decorating, preferred to choose green decoration materials. Source control is not patient in air flow condition, the influence of the indoor light, temperature, humidity, and is not affected by indoor type and layout of the room, is the most effective way. Analysis the reason, should be of the study area is generally small, while wooden furniture and more concentrated, make formaldehyde accumulate high concentrations than living room and bedroom. Is greater than the bedroom and sitting room general ventilation time, so the lowest concentration. Our test results also found that the same pollution degree is the same as the set of the each room in the bedroom, it is the same in the bedroom decorate indoor environment and the unit space load, so the pollution level, especially the chemical pollution levels are basically the same. (3) Ventilation is also an effective method to control channeling the formaldehyde pollution. But in the use of air conditioning and heating are not necessarily economy [3]. In the lowest overall cost of indoor formaldehyde concentration standard is also a need to study the problem.

Ventilation condition is one of the bedroom air pollution prevention and control of the improvement in extremely simple and effective way, ventilation can not only by strengthening the volatilization of formaldehyde to reduce air pollutants such as formaldehyde content in the bedroom, still can bring fresh air for the interior, and thus improve the bedroom environment quality better. But because of the influence of ventilation methods of outdoor air and ventilation condition, has certain limitations, therefore, to study a kind of effective formaldehyde pollution treatment technology is very necessary. Nowadays, indoor pollutants formaldehyde purification research has drawn the attention of the related research at home and abroad scholars. Bedroom formaldehyde pollution prevention technology usually gives priority to with physical and chemical methods.

The Solutions to the Decoration Pollution. From the source to reduce or avoid the indoor pollution gases such as formaldehyde and with the outside world barrier to prevent the pollution gas into the indoor environment of method called pollution control. Theoretically, the influence of bedroom air formaldehyde content for prevention and control of indoor pollution sources, late compared to other measures to control, pollution at source is a more effective way. Photocatalytic purification technology is the emerging high-tech formaldehyde pollution purification technology in recent years, is a kind of catalyst, the harmful gas such as formaldehyde transformed into cutting-edge technology. Formaldehyde is common organic pollutants in the bedroom. According to the research of the related reports, the degradation efficiency of formaldehyde is influenced by humidity and reactant concentration, etc. Activated carbon adsorption on indoor gas adsorption mostly belongs to physical adsorption, adsorption capacity is weak, and belongs to the hydrophobic material, activated carbon adsorption ability of hydrophilic material is bad, and main pollutants indoor formaldehyde belongs to the hydrophilic material. In addition, physical adsorption has poor stability, easy to take off when the condition such as pressure, temperature changes so as to cause the secondary pollution. As the humidity of the air increases gradually, the degradation of formaldehyde can achieve maximum rate. Photocatalytic technology is developed rapidly in recent years a multiphase advanced oxidation technology. Physical adsorption and chemical adsorption, the adsorption of porous material was mainly used for harmful gas adsorption, so this kind of purification materials must have a strong ability of adsorption. In the following figure three, we show the solutions to the decoration pollution. 


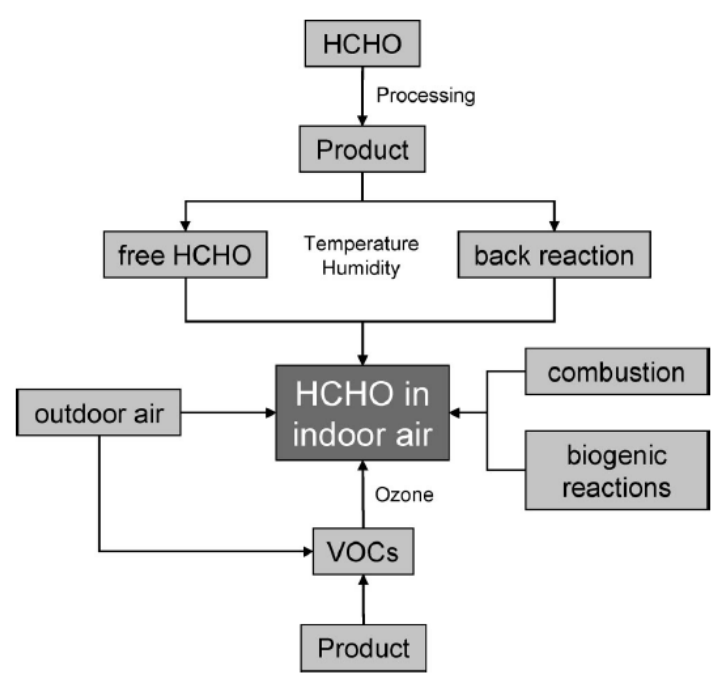

Figure 3. The Flowchart of the Solutions to the Decoration Pollution

\section{Conclusion}

In this paper, we conduct research on the volatile organic compounds in the air after indoor decoration pollution status and pollution control countermeasures. Residents of new housing decoration and part of the authority of office space decorate will lead to the deterioration of the indoor environment pollution and indoor air quality drop, in which to live and work personnel health is bound to cause great harm. Although people have the choice to decorate material of environmental protection consciousness, however, the current building materials on the market of decorate material to the good and bad are intermingled, in the general population is not distinguish decorate material quality professional knowledge, so most of the building is decorated after the indoor air quality are far from national quality standard. Our methodology is meaningful for solving the challenges.

\section{References}

[1] Raso R A, Stepuk A, Mohn D, et al. Regenerable cerium oxide based odor adsorber for indoor air purification from acidic volatile organic compounds[J]. Applied Catalysis B Environmental, 2014.

[2] Nohr M, Horn W, Wiegner K, et al. Development of a material with reproducible emission of selected volatile organic compounds - $\mu$-Chamber study.[J]. Chemosphere, 2014, 107:224-229.

[3] Tan H, Qian S, Sun D, et al. Study on the pollution status and standards of indoor organic compounds $[\mathrm{J}]$. China Measurement $\&$

Test,

2015. 